\title{
MODERATING INFLUENCE OF VIRTUAL LEARNING SUPPORTS ON THE RELATIONSHIP BETWEEN EMOTIONAL INTELLIGENCE AND FACULTY ENGAGEMENT IN INSTITUTIONS OF HIGHER LEARNING
}

\author{
${ }^{1}$ Falola H.O; ${ }^{2}$ Adeniji, A.A, ${ }^{3}$ Osibanjo, A.O, ${ }^{4}$ Salau, O.P, and ${ }^{5}$ Ogueyungbo, 0.0 \\ ${ }^{1-5}$ Department of Business Management, Covenant University, Ota, Ogun State, Nigeria
}

\begin{abstract}
The objective of this study is to explore the moderating effect of virtual learning supports in the relationship between emotional intelligence and faculty engagement in institutions of higher learning in Nigeria. The study used secondary data sourced from scientific databases. The information collected from various articles in various scientific data based were analysed and discussed. The aim is to find out if virtual learning supports moderate the relationship between emotional intelligence and Faculty engagement in Institutions of higher education. The primary constructs of the observed variables were reviewed in line with the specific objectives of the study. It was revealed that virtual learning supports moderate the relationship between emotional intelligence and Faculty engagement. Therefore, Faculty in Institutions of higher learning in Nigeria should consider leveraging virtual learning supports provided by the management of the institutions to manage their emotional intelligence to enhance faculty teaching, research and community service engagement. The study developed a model that can be empirically investigated to determine the extent at which virtual learning supports moderate the relationship between emotional intelligence and Faculty engagement.
\end{abstract}

Keywords: Virtual learning, emotional intelligence, Faculty engagement, institutions of higher learning

\section{INTRODUCTION}

The academic environment in the era of revolutionary technology has become more competitive. Every institution regularly appraises and redevelops applicable and comprehensive life-transforming curriculum that is relevant to all fields of human endeavours based on the need of the larger society (Mohanasundaram, 2018). In order to achieve the goal of providing quality education that will meet the need of the society, most institutions in the developed economy provide opportunities for learning through conventional study (face-toface interaction), blended (both face-face and online) learning, and virtual learning. To this end, acquiring quality education in any part of the world has become more open as many universities and other institutions of higher learning have different virtual courses and programmes available for the students and faculty members. Virtual learning has become one of the inevitable media of engagement in the new normal era as orchestrated by the outbreak of COVID-19. There has been an incredible increase in the way people engage various learning platforms for acquisition of new skills, knowledge and other competencies required to be effective and efficient in the chosen careers (You, 2016). The higher education institutions are not left out of this. Virtual learning platforms have transformed the way and manner in which Faculty interact with students 
in Nigerian. Before COVID-19 pandemic in Nigeria, online engagement was partially adopted to complement the traditional face-to-face interaction in the classrooms. However, COVID-19 propelled many universities, particularly private universities in Nigeria, to engage students through virtual learning platforms. It is pertinent to note that Faculty teaching, research and community service productive engagement depends on the way and manner in which Faculty manage their emotions (Oyewunmi, Osinbanjo, \& Adeniji, 2016). As noted by Mohammad, Sadia and Misbah (2017), people are not the same when it comes to the level of mindfulness about their emotions and articulation of verbal and non-verbal emotions. However, the ability of faculty members to manage their emotions professionally could perhaps enhance their teaching, research and partnerships/ collaborations engagement. Studies have investigated the influence of emotional intelligence on academic staff performance (Mahdinezhad, \& Mohammad \& Shakib \& Wai, \& Hashim, 2017; Shehu \& Kida, 2019; Vahidi, Namdar \& Arshadi, 2016). However, the extent at which virtual learning supports provided by the management of institutions of higher learning moderate the relationship between emotional intelligence and faculty engagement has not been sufficiently studied. This study, therefore, explores the moderating role of virtual learning supports on the relationship between emotional intelligence and faculty engagement.

\section{LITERATURE REVIEW}

\subsection{Virtual Learning Supports and Improved Job Engagement}

As noted by Iroaganachi and Izuagbe (2018), virtual learning support is regarded as an enabling environment that is based on the adoption of digital technology and resources to foster and facilitate continuous interaction and communication in a virtual space. Rodrigues, Almeida, Figueiredo, Lopes, (2019; 95) posited that "virtual learning as an innovative web-based system based on digital technologies and other forms of educational materials whose primary goal is to provide students with a personalised, learnercentred, open, enjoyable, and interactive learning environment supporting and enhancing the learning processes". Also, Mah (2016) posited that the virtual learning support is aimed at providing a set of tools that will enhance the assessment of knowledge transfer, learning and engagement processes remotely. Virtual learning support from the pedagogy point of view facilitates innovative experiences that foster and strengthen teaching, research and community service engagements via electronic communication and feedbacks (Gašević, Dawson, Rogers, \& Gasevic, 2016, Stepanyan, Littlejohn, Margaryan, 2013). Virtual learning platforms are capable of providing a central focus for both Faculty and students regardless of their location at any point in time (Sclater, Peasgood \& Mullan, 2016). Also, studies have shown that virtual learning provides opportunities for both young and senior Faculty to access needed information electronically (Billy \& Yuan-Li, 2020; Delgado, Samaniego, Salinas, Acosta \& Avila, 2020). Investing and creating a virtual learning environment to nurture the young Faculty for improved job engagement could be the right step in the right direction.

\subsection{Emotional Intelligence}

Emotional intelligence gives off an impression of being a multidimensional construct portrayed by bidirectional impacts among familial, environmental, and intellectual components. Besides, El can impact the articulation, elucidation, and effect of emotional reactions in all periods of human experience (Christopher, Jerrell \& Monica 2017). Emotional intelligence comprehends and manages sentiments, feelings and emotion information to advance the development of attitudes and education. Mohammad, Sadia and Misbah (2017) opined that people are not the same when it comes to the level of mindfulness about their emotions and articulation of verbal and non-verbal emotions. Others comprehend those persons who have the capacity to perceive and react to their feelings in better ways. Emotional intelligence is an instructive, changeless and constant process that means to help the improvement of emotional skills as a fundamental component of human advancement to qualify people forever and to expand individual and social prosperity (Carlos, Pablo \& Laurane, 2017, Zahyah, \& Farukh, 2016). El connotes the general ability to understand the emotions and sentiments one and others with the capacity to manage and interprets them.

\subsection{Faculty Engagement}

As noted by Falola et al. (2020), the core responsibilities of faculty members of institutions of higher learning, particularly universities are research, teaching, collaboration/partnership and community service, among others. The universities ranking position of any university is a function of quality teachings, outstanding research productivity, reputation, industry partnership, collaborations, among others (Aina, 2010, Falola et al., 2018b). Falola et al. (2018a) posited that faculty teaching and research engagement can be enhanced if the management of universities provides institutional supports in terms of conference supports, research grants, article processing charges supports among others. 


\section{MODEL DEVELOPMENT FOR EMPIRICAL INVESTIGATION}

This study offers a model that integrates the interplay between emotional intelligence, virtual learning supports and faculty engagement. Virtual learning supports are playing the role of moderation between the independent and dependents variable. The empirical investigation will help to ascertain the extent at which virtual learning supports provided by the management of institutions of higher learning moderate the relationship between emotional intelligence dimensions and faculty teaching, research and community service engagement. The model can adopt smart PLS for the empirical analysis of the model.

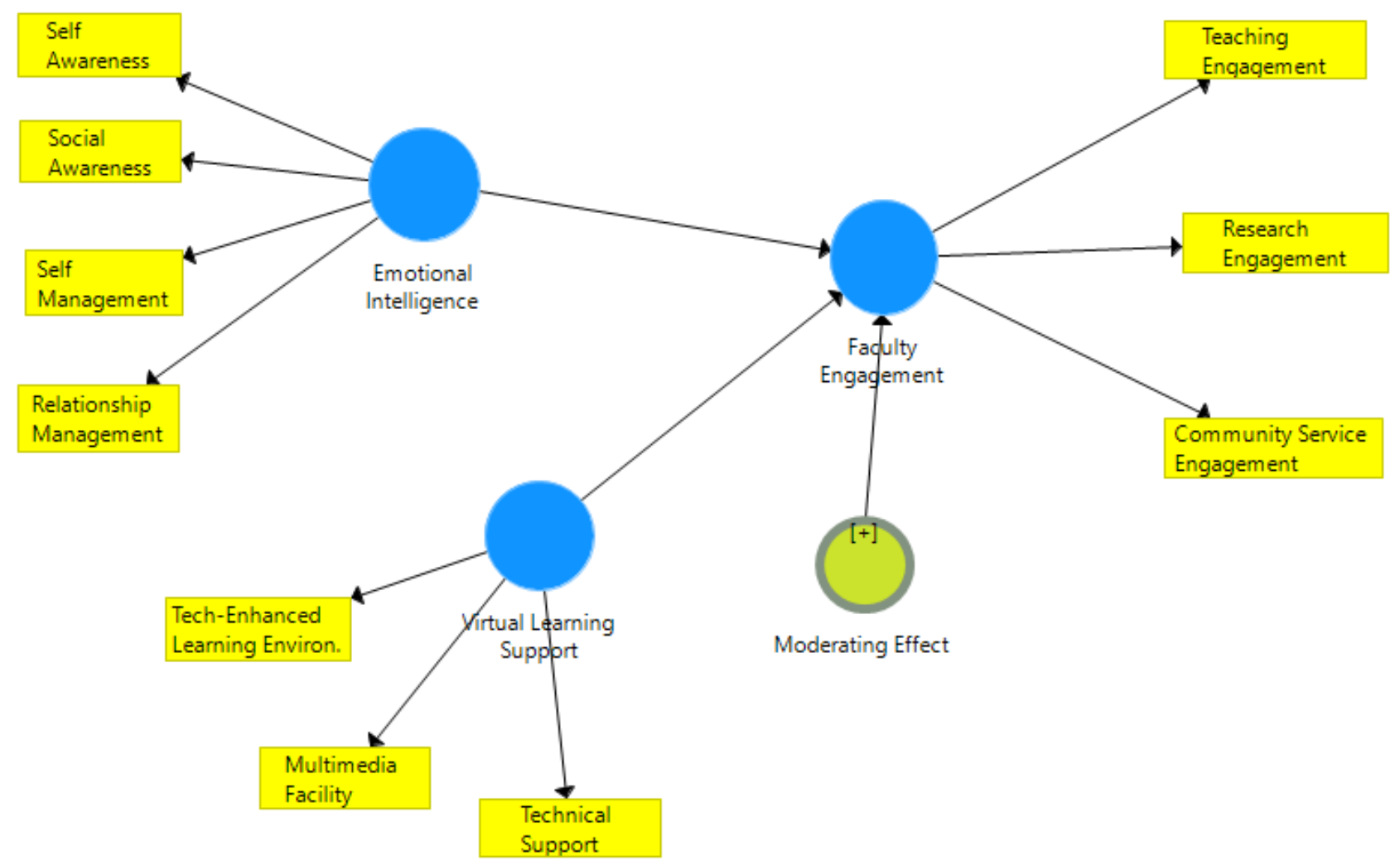

Figure 1: Emotional Intelligence, Virtual Learning Supports and Faculty engagement model

\section{CONCLUSION AND RECOMMENDATIONS}

Faculty in the institutions of higher learning need to be conversant with emotional intelligence dimensions (self-awareness, social awareness, self-management and relationship management) that can be leveraged for outstanding research, teaching and community service engagement. It is imperative to note that being emotional intelligence gives an edge in terms of enhanced engagement of Faculty members while virtual learning supports (technology-enhanced environment, multimedia facility, technical support, training) could perhaps strengthen and enhance the level of job engagement of Facultyritual learning is a very influential instrument that all educational institutions of higher learning should embrace to drive high engagement. If virtual learning is given the required attention, it will make institutions more competitive and the institution of choice for potential students and Faculty. Management of the institutions should endeavour to provide a technology-enhanced environment, modern virtual teaching facilities and required training for optimal use of the learning facilities provided. 


\section{REFERENCE LIST}

Aina, T. A. (2010). The Role of Private Universities in Driving Social and Economic Change: Challenges and Opportunities. The $5^{\text {th }}$ Convocation Ceremony Distinguished Lecture, Covenant University, Ota, Nigeria.

Billy, W, Yuan-Li T. C., (2020). University lecturers' construction of the 'ideal' undergraduate student. Journal of Further and Higher Education. 44(1), 54-68.

Carlos, S., Pablo, U. \& Laurane, J. (2017). Emotional intelligence and social skills on self-e efficacy in Journal of adolescence, 60, 39-46.

Christopher, L.T, Jerrell, C. C. \& Monica L.H. (2017). The influence of emotional intelligence, cognitive test anxiety and coping strategies on undergraduate academic performance. Learning and individual differences, 55, 40-48.

Delgado, J., Samaniego, R., Salinas, J, Acosta, M., and Avila, A. (2020). Open educational resources for the strengthening of digital competences in higher education. EDULEARN20 Proceedings, 4143-4148.

Falola, H.O, Adeniji, A.A, Adeyeye, J.O, Igbinoba, E.E and Atolagbe T, (2020). Measuring Institutional Support Strategies and Faculty Job Effectiveness. Heliyon, 6(3), 1-6.

Falola, H.O, Oludayo, O.A, Olokundun, A.M, Salau, O.P and Ibidunni, A.S. (2018a). Employee resourcing strategies and universities' corporate image. Data in Brief.

Falola, H.O, Olokundun, A.M, Salau, O.P, Oludayo, O.A and Ibidunni, A.S (2018b). Effect of work engagement strategies on Faculty Staff behavioural outcomes in private universities. Data in Brief.

Gašević, D., Dawson, S., Rogers, T., \& Gasevic, D. (2016). Learning analytics should not promote one size fits all: The effects of instructional conditions in predicting academic success. Internet and Higher Education. 28, 68-84.

Iroaganachi, M. A. (2016). Trends and issues in digital libraries; In Egbert de Smet \& Dhamdhere S. (Eds.), E-Discovery Tools and application in modern libraries. The USA. Idea Group Inc (IGI). 320-335.

Iroaganachi, M., \& Izuagbe, R. (2018). A comparative analysis of the impact of electronic information resources uses towards research productivity of academic staff in Nigerian Universities. Library Philosophy and Practice, 7(9), 17- 22.

Mah, D. K. (2016). Learning analytics and digital badges: potential impact on student retention in higher education. Technology, Knowledge and Learning, 21(3), 285-305.

Mahdinezhad, Maryam \& Shahhosseini, Mohammad \& Shakib Kotamjani, Sedigheh \& Wai, Kuan \& Hashim, Emilda. (2017). Emotional Intelligence and Job Performance: A Study among Malaysian Administrators. International Journal of Academic Research in Business and Social Sciences. 7. 953-966.

Mohammad, A., Sadia, A. \& Misbah, H. (2017). Impact of emotional intelligence on teacher's performance in higher. Future business journal.3(2), 87-97.

Mohanasundaram, K. (2018). Curriculum Design and Development. Journal of Applied and Advanced Research, 3(1), S4-S6.

Rodrigues, H.; Almeida, F.; Figueiredo, V.; Lopes, S.L. (2019; 95). Tracking e-learning through published papers: A systematic review. Comput. Educ., 136, 87-98.

Sclater, N., Peasgood, A., \& Mullan, J. (2016). Learning analytics in higher education. A review of UK and international practice. Full report. JISC. Publiziert unter der Lizenz CC BY, 4(22.04).

Shehu, Liberty \& Kida, Mohammed. (2019). The effect of emotional intelligence on employee's performance. Review of Public Administration and Management. 6(12), 22-32

Stepanyan, K.; Littlejohn, A.; Margaryan, A. (2013). Sustainable e-Learning: Toward a Coherent Body of Knowledge. Journal of Educational. Technology Soc. 16, 91-102.

You, J. W (2016). Identifying significant indicators using LMS data to predict course achievement in online learning. The Internet and Higher Education, 29:23-30. 2016.

Vahidi, M., Namdar Areshtanab, H., \& Arshadi Bostanabad, M. (2016). The Relationship between Emotional 
Intelligence and Perception of Job Performance among Nurses in North West of Iran. Scientifica, 2016, 1-5

Zahyah, H. \& Farukh, N. (2016). Relationship between Emotional Intelligence and Academic achievement in Emerging Adults: A Systematic Review. International Journal of A Academic Research in Business and Social Sciences, 6(6), 268-290. 